\title{
Looking out for the next generation of research questions in logistics
}

Peter Klaus

Published online: 13 November 2009

(C) Springer-Verlag 2009

One of the most exciting challenges for anyone interested in the evolution of a field of science is this: to anticipate those questions that will stimulate the "next generation" of research, guiding the work of researchers in coming years. If we have a hunch, we will be able to be "early movers" at the front of research developments in our field. We may be able to differentiate ourselves from those who do research in pursuit of "normal science" activities that tend to be less innovative and interesting than those that add new perspectives and new solutions.

Obviously, our ability to meet the challenge of anticipating future developments of an academic field is very limited-probably even more so in a relatively young and yet unsettled field as logistics. But-why not try?

Submissions to academic journals, which come from a very diverse range of researchers by their disciplinary backgrounds, by multiple national and cultural perspectives, and by various academic and real-world experiences, may be good "early indicators". Established academic traditions that we participate in, like organizing "doctoral consortiums" for groups of doctoral candidates accompanying meetings and annual conferences of our professional associations, provide the opportunity to sound out their views on what they believe the "next" important issues will be.

Jointly with colleagues from our journal's editorial board and from the advisory board of two of our large associations of logistics professionals, we recently had the opportunity to do some informal inquiries of this kind. We met about 50 doctoral students from many countries,

P. Klaus $(\square)$

Nürnberg, Germany

e-mail: peter.klaus@wiso.uni-erlangen.de

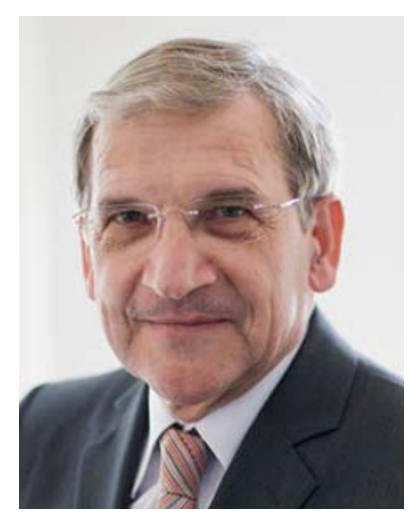

universities, and backgrounds. And we were able to review about 50 manuscript submissions to our journal, which we received over the last 18 months, as another "sample" of future-oriented logistics research questions.

What we are learning is-in some part-not entirely surprising: there are expectations of ever more demand for research related to the new technologies of "RFID" and future information networks. The issues of "sustainability," "terrorism", "supply chain risk", and how to manage the ever-increasing complexity of "expanded supply chains" and "macro-economic volatility" were named frequently.

But there also were some less expected nominations of future topics: on the identity of our field, especially the meaning and true promise of the move of logistics toward a "supply chain science"; which is reflected in so much work. On the transferability of logistical know-how to new fields of application, such as a "logistics of knowledge", "humanitarian logistics", etc. On cause-effect relationships between logistical interventions into organizations and outcome variables that have not been considered yet in sufficient depth, like certain effects on finances, systems adaptability, or human stress with employees involved.

With these kinds of thoughts in mind, I find that several of the contributions in this issue Nr. 3 of LOGISTICS RESEARCH may have importance at a level that is not immediately obvious.

Obermeier/Otto's paper on "How can supply networks increase firm value? A causal framework to structure the answer" is providing a very thoughtful discussion on the "true" benefits of supply chain integration-addressing thoughts that Bretzke in his article presented in the preceding issue of our journal. They do not claim to have a 
definitive answer, but they suggest a helpful way to structure our thinking about the question.

Pfohl and Gomm in their contribution on "Supply Chain Finance-Optimizing financial flows in value chains" extend a line of work that only rather recently has been started about the effects of supply chain management upon the financial situation of companies.

Kotzab and Gudehus make an ambitious attempt to show that logistical know-how may add new insight into a field which otherwise would be looked at as a rather well researched, if not exhausted area: the application of a logistical perspective to industrial "Planning and scheduling production systems".

Nopper/Ten Hompel's "Analysis of the relationship between available information and performance in facility logistics" may be viewed as a very practical analysis of an engineering problem. But-at the same time-it can be seen as an interesting contribution to the field of complexity management. The work reports on a simulation-based analysis about when and how more information adds quality to the resolution of a very complex task.

Ventura's article on "Estimating freight rates in inventory replenishment and supplier selection decisions" points our attention to an often overlooked and usually underestimated aspect of supplier selection and optimal ordering practices, i.e., inbound transportation cost. He offers a method for integrating those cost into rational decision making.

In future issues of our journal, we hope to be able to provide more ideas and motivation for innovative logistics research. We appreciate your suggestions and submissions that will help us to do this.

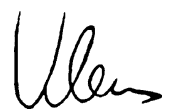

Peter Klaus, Editor-in-Chief

November 2009 